\title{
Integration of Virtual Reality (VR) in Architectural Design Education: Ex- ploring Student Experience
}

\section{Mr. Joseph Edward Williams III, Western Kentucky University}

I am an undergraduate student at Western Kentucky University (WKU) majoring in Architectural Sciences. I will be graduating in May of 2019. My interest in design and technology in architecture motivated me to research how Virtual Reality (VR) could be used to improve the design process of architecture students in academia.

\section{Dr. Fatemeh Orooji, Western Kentucky University}

Fatemeh (Mahtab) Orooji is an assistant professor in the School of Engineering and Applied Sciences at Western Kentucky University. She had post-doctoral research experience in the department of construction management at Louisiana State University. She accomplished her Ph.D. degree in Engineering Science with Construction Management Concentration from Louisiana State University in May 2015. She obtained master degrees in Construction Management from Louisiana State University in 2014, and in Architecture from University of Tehran, Iran in 2009.

\section{Ms. Shahnaz J. Aly, Western Kentucky University}

Shahnaz Aly, OAA, LEED AP, M. Arch, is a licensed Architect in India and Canada and Associate Professor in the School of Engineering and Applied Sciences at Western Kentucky University. She has 10 years professional experience in the architecture and construction industry in residential, commercial and mixed-use projects. She has 8 years of experience in teaching and research in areas of architectural design, sustainable design, historic preservation and BIM. 


\title{
Integration of Virtual Reality (VR) in Architectural Design Education: Exploring Student experience
}

\begin{abstract}
The architecture industry significantly relies on visual communication. Virtual reality helps designers create a greater sense of realism and a better understanding of a project by designing while immersed in them. That technological advancement has the potential to improve the design process. Therefore, the demand for adapting the use of virtual reality environments in the architecture industry has increased over the past two decades. If academia is aligned with industry, students will be better prepared for integration into the workplace. As a result, the integration of virtual reality into the architectural curriculum is an educational imperative.

The long term goal of this project is to incorporate VR into design studios and build a virtual reality lab for architecture students at Western Kentucky University. This study describes the overview of the ongoing integration of virtual reality (VR) environments within the Architectural Science program. A pilot study was conducted prior to incorporating VR into the classroom to investigate the value and the challenges of integration of virtual reality system in design education. This research details and analyzes the experience of a junior student by applying VR to facilitate learning in the context of architectural design. The student applied VR to become immersed in the designed building through the use of a headset and hand controllers. Based on the collected experimental data, the authors investigated the practical application of VR in the learning environment and demonstrated the effectiveness of this advanced technology in pedagogical practice.
\end{abstract}

\section{Introduction}

Virtual reality (VR) is the revolutionary development of the computer-generated synthetic world. Although there is no one standard definition for virtual reality, depending on their background scientists, researchers, and computer users have had a different definition for virtual reality. Pimentel and Teixeira [1], defined virtual reality as an immersive, interactive experience generated by a computer. The more recent definition of VR is described by Dionisio and Gilbert as "computer-generated simulations of three-dimensional objects or environments with seemingly real, direct, or physical user interaction" [2]. From the definitions, it can be derived that VR has an experimental nature with the main elements of the virtual world, immersion, interactivity and multi-sensory feedback.

The first virtual reality system was introduced in the 1960s, and the first Head-Mounted Display (HMD) for VR was built around 1965. In the 1980s, VR became more popular with rapid growth in technologies and applications [3, 4], and the first cave was presented in 1990 [5]. Since then, virtual reality technologies have been used in movies and the gaming industries significantly. However, VR became more accessible in other areas for the first time after 2016 when giant tech companies, such as Facebook, Microsoft, Apple, Google, and HTC announced and released their commercial products in VR onto the market and made VR affordable. 
This technological evolution has affected different disciplines, particularly the architecture industry which significantly relies on visual communication. Virtual reality helps designers create a greater sense of realism and a better understanding of a project by designing while immersed in them. This technological advancement has the potential to improve the design process. Therefore, the demand for adapting the use of virtual reality environments in the architecture industry has increased over the past two decades. For example, Foster + Partners use VR environments to help develop complex design visualizations and walkthroughs for their clients. Also, Paul Renner from Kohn Pedersen Fox a global architectural practice believes that through their use of VR design teams has been able to experience any stage of design in real-time through the immersive experience that the technology provides. Lastly, Jamie Casas of Wood \& Grieve Engineers states that "VR environment is important in our industry, where design changes require clear communication". These testimonies confirm that virtual reality has a tremendous amount of potential in the architecture industry.

As a result, architecture schools must also develop a curriculum to prepare students for a future dominated by technology. This study describes an overview of the ongoing integration of VR environments within the Architectural Science program at Western Kentucky University. This research details the experience of a junior student by applying VR to facilitate learning in the context of architectural design. The student applied virtual reality to become immersed in the designed building through the use of a headset and hand controllers. Based on the result of the student experience, the authors investigated the practical application of VR in the learning environment.

\section{Integration of Virtual Reality (VR) In Architecture Education}

Virtual reality (VR) technology has great potential to be integrated into the Architectural Science program curriculum. Architecture school curriculums and course descriptions demonstrate that integration of VR in the architecture curriculum in the U.S. has been growing considerably. The architecture schools have integrated virtual reality (VR) in the academic curriculum through different approaches. Table 1 represents undergraduate level VR-incorporated courses in architecture programs from different universities.

Table 1: Course content descriptions for VR- incorporated undergraduate courses from Architecture curricula.

\begin{tabular}{|c|c|c|}
\hline University/program & Course & Course description \\
\hline $\begin{array}{l}\text { university of Minnesota/ } \\
\text { School of Architecture }\end{array}$ & $\begin{array}{l}\text { ARCH } 3250 \\
\text { Design And } \\
\text { Perception In Virtual } \\
\text { Reality }\end{array}$ & $\begin{array}{l}\text { "This workshop will focus on issues of design and perception in the context of } \\
\text { several types of virtual environments. Several short design sketches will } \\
\text { provide students with an opportunity to make use of the head-mounted display } \\
\text { and immersive wide-screen VR Window in the Digital Design Consortium VR } \\
\text { lab to study the effects of VR on their approach to design and the way they } \\
\text { perceive what they have designed."[6] }\end{array}$ \\
\hline $\begin{array}{l}\text { University of Michigan/ } \\
\text { Architecture }\end{array}$ & $\begin{array}{l}\text { ARCH } 409 \\
\text { Virtual Realities: } \\
\text { Rendering Real- } \\
\text { Time Environments }\end{array}$ & $\begin{array}{l}\text { "This course aims to arm architecture students with the necessary concepts and } \\
\text { practical skills to employ virtual reality technologies for both design and } \\
\text { visualization. Virtual Reality (VR) is one of many so-called "XR" technologies } \\
\text { that include Augmented Reality (AR) and Mixed Reality (MR). What supports } \\
\text { them all are real-time rendering engines, the software that video games are built } \\
\text { with. While conventional rendering technology like ray-tracing slowly renders } \\
\text { each image, which can take hours or even days, real-time technology renders } \\
\text { images at the speed of human vision, allowing fluid experience of virtual } \\
\text { content."[7] }\end{array}$ \\
\hline
\end{tabular}


"This is an experimental course for students across campus that uses VR methods and discourse to render visible and critically examine knowledge generated at Berkeley, including fields as diverse as astrophysics, bioengineering, philosophy, business, literature, engineering, architecture, film, robotics, artificial intelligence, biology, art, and others. Students will develop 'houses of knowledge' that will capture and represent specific fields of study developed at Berkeley using a variety of media formats. The course aims to provide students across campus the opportunity and tools to generate VR applications, and expects a critical and active response to the topics approached. Participants will create their projects in VR while working on multidisciplinary groups, including students from architecture (due to the 3-dimensional nature of the projects), computer science and virtually any other department across campus.’'[8]

ARCH 240 "Virtual and Augmented Reality are the next platforms where we will work, Advanced Study of communicate and entertain, after the computer and the smartphone. Current Energy and Environment headsets will be replaced by interfaces yet to be imagined, much like the mouse and keyboard were being invented at Xerox Park in the 70's. As designers of three-dimensional environments, architects will play a decisive role in defining this virtual world, contrarily to graphic designers who dominated the visual characterization of a 2-Dimensional web. VR and AR may also in the future fundamentally disrupt the way that we design and conceptualize architecture.'[8]

Cornell University/ Architecture

Carnegie Mellon University/ Design

Iowa State University/ Architecture
ARCH 3109

"This class has been organized as a design studio with collaboration between Architecture (Special architectural designers and computer graphics majors.'[9]

Experimental)

Studio

$51-265$

"Learn the basic design processes for experience-driven multi-modal Environments Studio environments, making meaningful physical and virtual experiences through I: Understanding planning, structuring, and explaining/visualizing; utilize a range and Form \& Context

$51-268$ combination of analog and digital tools for high fidelity output."[10] Environments Studio meaningful physical and virtual experiences; utilize a range and combination of II: Designing Environments for Interaction

ARCH 534

Advanced

Computer-aided Architectural Design
"Emphasis on concepts, algorithms, data structures, advanced modeling, rendering, animation, and virtual reality applications in architectural design"'[11]

Virtual Reality technology could be integrated into the diverse tracks of architectural education from primary courses to advanced subjects. The most common approach is incorporating VR in the Design Studio courses. For example, school of architecture in Carnegie Mellon University and Berkeley incorporate VR in design studio courses to provide students with an opportunity to study the effects of VR on their approach to design and the way they perceive what they have designed. Some Architecture programs introduce VR through a specific VR environment course such as "Designing Environments for Interaction" at Carnegie Mellon University, "Design and Perception in Virtual Reality" at the University of Minnesota, or through a workshop such as "Design and Perception in Virtual Reality" at the University of Minnesota.

\section{Integration of Virtual Reality (VR) in Architecture Science Program at Western Kentucky University: Student Experience}

The Architectural Science (AS) program in the School of Engineering and Applied Sciences at Western Kentucky University (WKU) is a bridge between design theory and 
construction practice. The major in Architectural Science requires 81 technical core courses. The graduates of the program are prepared with the practical education of architecture combining the knowledge of building design and applied technical knowledge of construction systems and materials [12]. The program instruction includes a series of 3D Modeling courses including AMS 251; 3D Modeling \& Imaging, and AMS 351; Building Informational Modeling, and a series of Design Studio courses including AMS 369; Architectural Design Studio I, and AMS 469; Architectural Design Studio II which have virtual reality related content potential.

This research is a pilot study prior to incorporating VR into the classroom to investigate the value and the challenges of integration of a virtual reality system in design education. The research was conducted as part of a Faculty-Undergraduate Student Engagement (FUSE) grant received in Spring 2018. FUSE grants are competitive internal grants at WKU targeted towards undergraduate students who have achieved sophomore status at the time of application. Students apply for FUSE grants under the guidance of a faculty mentor and are required to work with the faculty mentor throughout the grant. The grant is "designed to support undergraduate students' intellectual development by fostering active engagement in the areas of research, creative and scholarly activities, and/or artistic performances." Students need to have a GPA of 3.0 to be considered for the grant. $\$ 3000$ was awarded to cover project-related expenses and student and faculty presentation at a regional or national conference. Student presentations at a regional or a national conference is an expectation of the FUSE grant [13]. The following sections explain the student experience while working on virtual reality hardware, software, and architectural design.

Hardware

While there are many different headsets on the market the two most popular and test products are the Oculus Rift and the HTC Vive. The Oculus Rift's price at the beginning of testing in 2018 was $\$ 399$ while the cost of the HTC Vive was \$499 [14]. At the time, the Oculus Rift was seen to be the better option for professional use outside of gaming since it had been out longer, and developers had more time to create software and features for it. The lower price option also worked to our advantage because it was more obtainable for a first-time consumer within the industry. Figure 1 shows the Oculus Rift headset, touch controllers, and sensors.

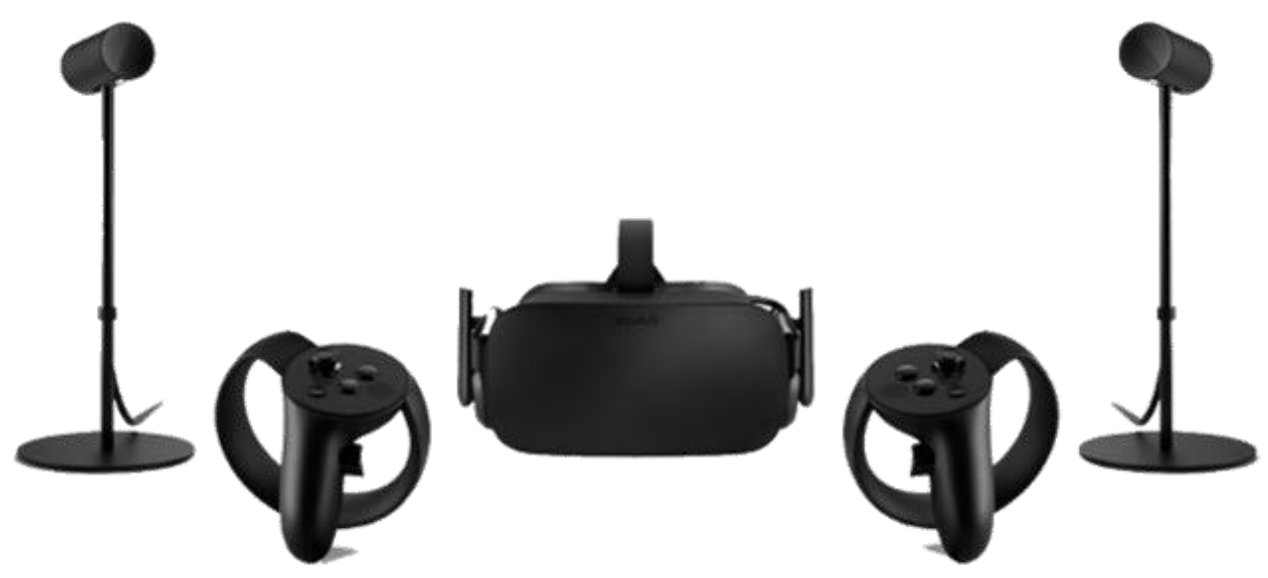

Figure 1: Oculus Rift 
The Oculus Rift has very advanced and easy to use desktop sensors. This worked perfectly for our environment because we were able to set them up on top of an existing desk within our virtual reality station (Figure 2). Lastly, the Oculus Rift offered the most natural and accurate controllers that were available for virtual reality. These controllers contour to the human hand very well allowing the user almost to forget they are using a controller at all. The Oculus Touch controllers are able to detect when the user is reaching, grabbing, and even pointing at something. These features added to the immersive experience of virtual reality because the movements and actions felt natural when doing a task such as: pointing out objects when collaborating, grabbing objects, and moving around between destinations during walkthroughs of the architectural model.

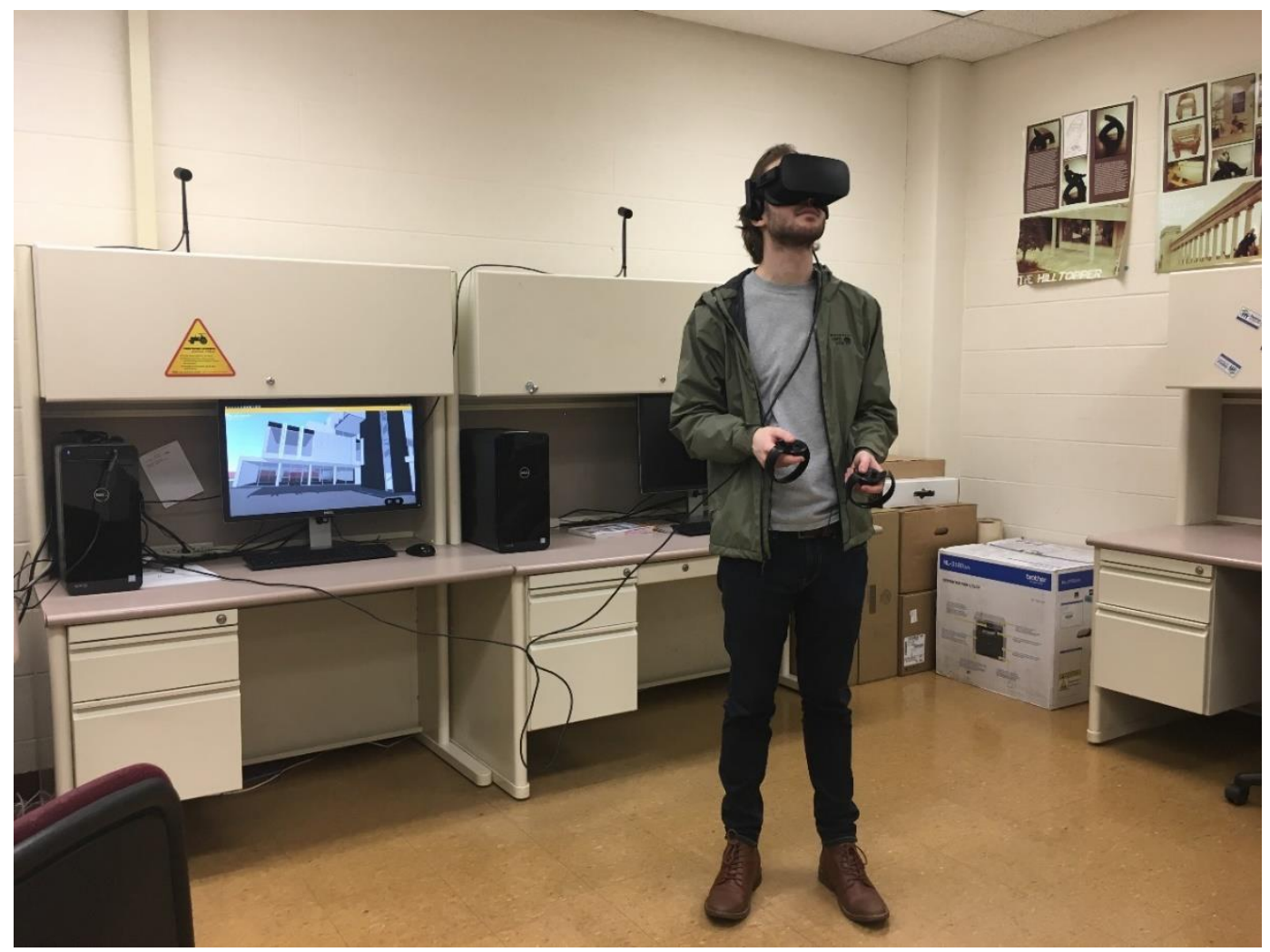

Figure 2. Virtual Reality Lab

VR Software

Software was a hard decision since virtual reality is such a new technology. Most programs adopt a headset designed for computer gaming and repurpose it for architectural interactions. There were a few criteria for selecting VR software. The software had to be compatible with the proposed hardware, and also with architecture programs. Moreover, it needed to be capable of simulating the most common architectural design challenges such as lighting, sense of space, and accurate material generation. In addition, it had to be compatible with design software.

Two most developed virtual reality programs compatible with Oculus Rift are IrisVR Prospect and Enscape [15]. These programs also offered free licenses for students and educators that wanted to test virtual reality for architectural design. IrisVR Prospect offers a lot of useful features such as tabletop model views, walkthrough tours, and team collaboration while in virtual 
reality. Iris VR Prospect supports SketchUp, Revit, Rhino, FBX, and Navisworks file formats. Enscape is an integrated virtual reality and real-time rendering tool for Revit, Sketchup, Rhino and ArchiCAD and offered standalone and $360^{\circ}$ Panorama Views.

The major downfall of IrisVR Prospect is that texture and material generation is not immersive for the user. For example, when the user is looking at a model made in Trimble SketchUp, the materials are generated exactly as they would show up on the regular computer monitor. While software such as Enscape for Revit replaces the visible materials with more realistic textures that use a real-time rendering engine for a more true-to-life architectural experience. Therefore, we found that the IrisVR Prospect software is best used for quick conceptual design and massing so that the designer can make sure they are making the correct design decisions. The Enscape for Revit software is better for seeing a finished project that could be presented to a client or classroom of students.

\section{Architectural Design Projects}

In this empirical study, we used two design projects. The 3D models of the projects were created in Trimble SketchUp and Autodesk Revit since these programs are the two most common 3-dimensional computer aided drafting software used by architecture students at Western Kentucky University (WKU). The first model was a hotel created in SketchUp for the Design Studio course at WKU (figure 3). The second model was a two-story family house created in Revit for Building Information Modeling (BIM) course at WKU (Figure 4). The hotel model consisted of retail and amenity spaces on the first level and 24 rooms on the upper three levels. The building has unique and prominent cantilevers with a total of 40,000 square feet. The Single-family house model consisted of two floors and a basement. Spaces included a large living area, family room, kitchen and dining on the first floor. The basement was left unfinished, and the upper levels comprised three bedrooms and two bathrooms totaling 4,000 square feet.

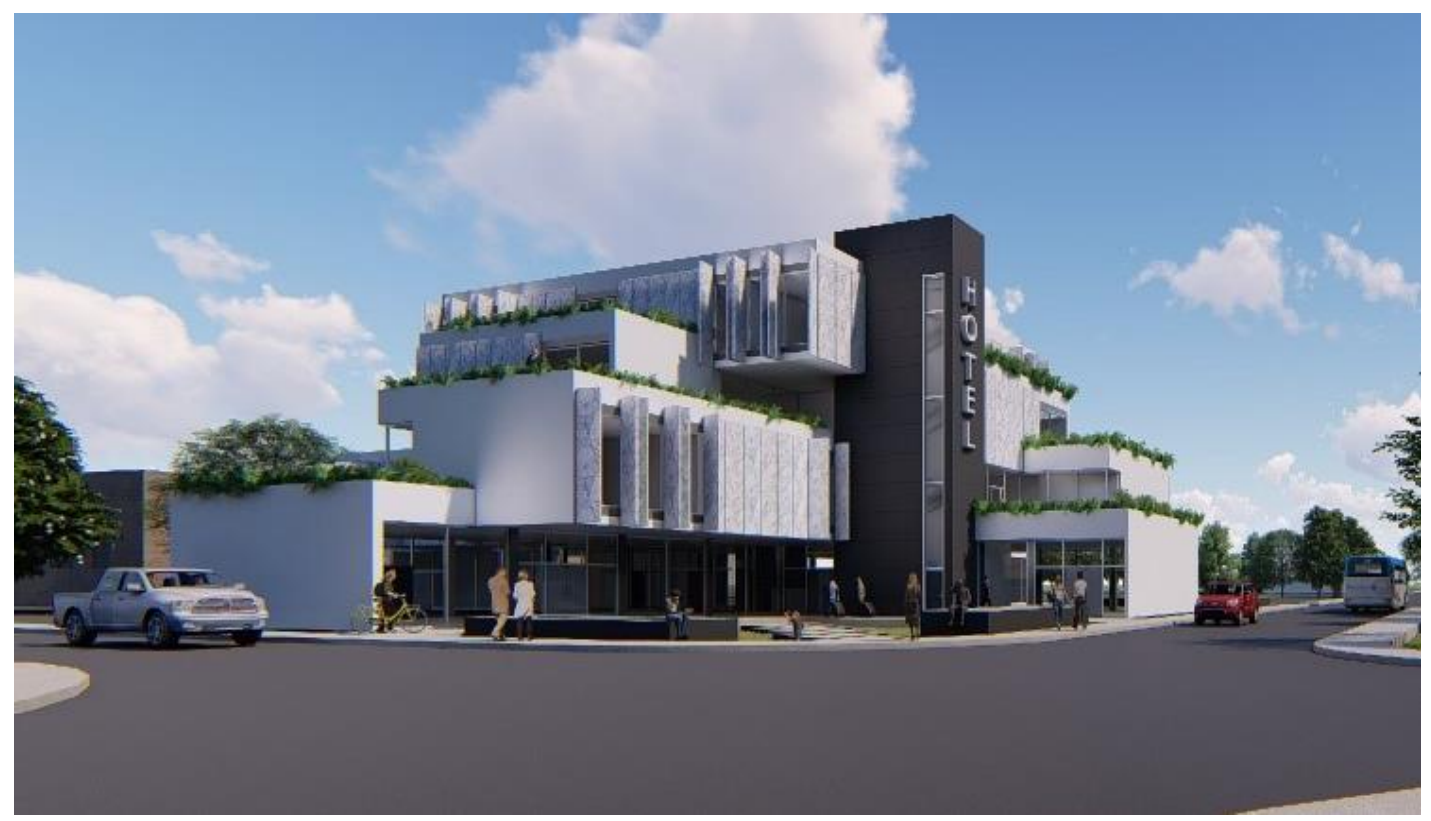

Figure 3. Image of Hotel Design 


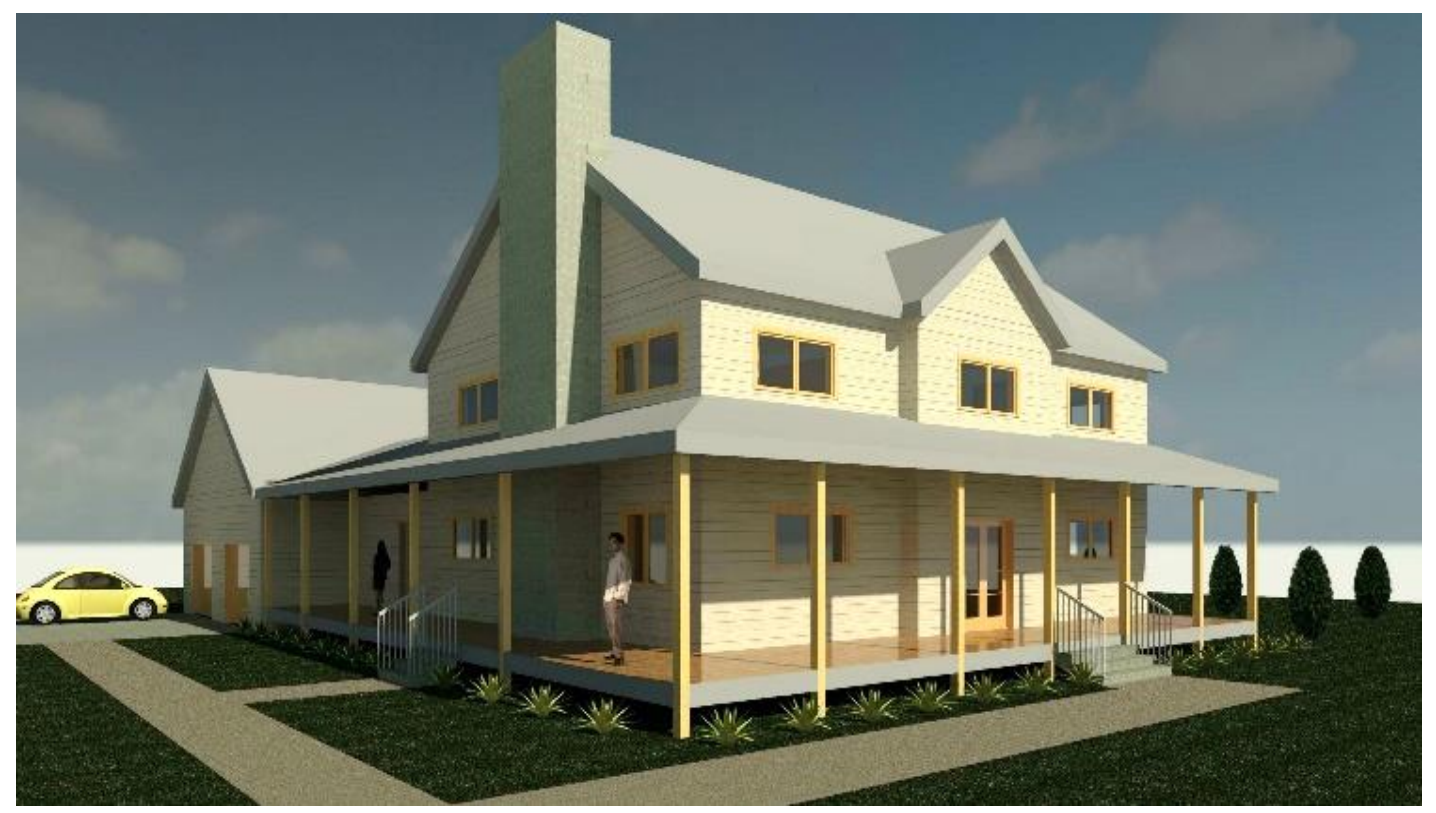

Figure 4. Image of House Design

\section{Research Experience and Findings}

The initial foray into the VR environment involved an enormous learning curve. Since this was the first time that VR was being used in the program getting familiar and manipulating the software was the first exercise that was undertaken. For this phase, a considerable amount of time was spent referencing online resources and they manipulating numerous settings to achieve desired results. Of the two projects selected we worked on the larger hotel project initially. This model was selected in the beginning because it was a very detailed project with materials, and furniture, capable of conveying the most immersive experience for the viewer. However, since this was our first time working in a virtual reality environment we realized that, a more standardized design with smaller square footage would be easier to follow and understand for a first time learner. Hence for the second empirical study, we decided to work on the smaller residential model. Some of the problems we as first-time users faced were a large footprint which made it more difficult to navigate. While working on this project in the design studio, we had not added design elements, materials and textures to a number of areas and once in the virtual environment, we realized that we had to add a tremendous amount of detail to give the viewer the full experience of the environment. Being a more common design the two-story family house would be easier to understand for architecture students who are being introduced to VR for the first time. It would also be easier for those with a non-architectural background to understand the working of VR before being exposed to more complex structures. The common spaces such as living rooms, bedroom are spaces that almost anyone has experience with making it the most optimal option. While working on the residential project in the VR environment, we realized that the bedroom didn't match with the vision of the design. It was a lot larger than what was expected. In the 2D environment, the room looked about average size, but the VR environment showed that it was much larger (Figure 5). 


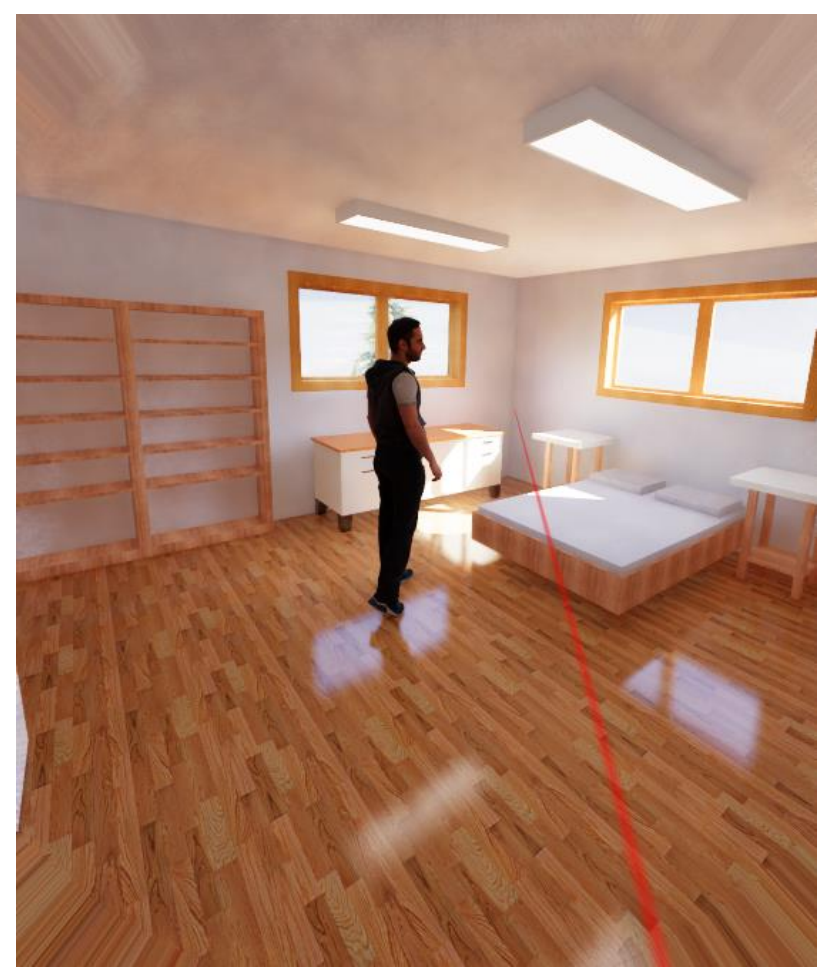

Figure 5. Single-family house model in the Enscape VR for Revit software

The software also showed where the light would come in through the windows as the day progressed. This could allow designers to move around the bed, so the sunlight did not produce glare in the morning. The sun study mapping was used to move the window to a different location where the sunlight would not be a problem. Viewing this in virtual reality was much faster and more natural because the alternative would have been to view the room in a floor plan view, an interior elevation, or even interior renderings. Therefore, instead of looking at multiple drawings and renderings at different angles, the team was able to naturally look around and see the problem. We were then able to fix the problem and could be more productive with the time saved.

The experiences using virtual reality for architectural design showed that designers could get a more accurate understanding of their designs by seeing it in a true 1:1 scale. For this reason, there are many advantages to VR over traditional 2-dimensional documentation. For example, when looking at an architectural design in a document you are not able to accurately tell the height, the amount of light a room gets, or have a sense of space. When testing architectural models in virtual reality, it allows the viewer or designer to understand better how the room is spaced. This is important for things like window placement, furniture, ceiling height, and spatial awareness.

\section{Summary and Recommendation}

This was a pilot project for the Architectural Science program achieved through a FUSE grant received in 2018. The student involved in the project gathered information on hardware and software required for the project as well as the best possible 3D architectural software to create the model. Some of the challenges that were faced during the initial research were limited funds which restricted the sophistication of the equipment and software that could be used to create better 
virtual environments. In addition, limited experience among researchers resulted in a steeper learning curve especially in terms of size and type of models that the first time user should work with to make it easier to manipulate the virtual environment.

While this project relayed the experience of a single student, the authors believe that in future the project could be expanded to a larger sample. The long term goal of this research is to incorporate VR into the design studio and build a virtual reality lab for architecture students at Western Kentucky University. To achieve the goal, the authors would like to conduct additional studies to see the difference in visualization among architecture students between a 3D model on a 2D display and a model in the VR environment. This will enable the authors to make a case for incorporation on VR into the design studio. The authors also envision that in order for VR to be successful in the design studio students will have to be trained prior to the design studio either in an earlier 3D modeling course or through a one credit hour course. For students to effectively use VR in the design studio faculty and experienced students will need to build a repository of resources as well as a quick reference guide for students to access as they are working in the virtual environment. This will enable students to work with VR effectively in the architectural studio.

The challenges that the authors perceive that they would face in the future would be securing additional funds to build a more sophisticated lab which could accommodate more equipment and allow more architectural science students to work on their design studio projects. Adding of VR in the curriculum will add tremendous value to the student experience and enable them to visualize better their designs making for the creation of much better architectural projects but more importantly enabling students to get a deeper understanding of design and spatial perception which will carry through into the professional field.

\section{References}

[1] K. Pimentel and K. Teixeira, "Virtual reality through the new looking glass," 1993.

[2] J. D. N. Dionisio and R. Gilbert, "3D Virtual worlds and the metaverse: Current status and future possibilities," ACM Computing Surveys (CSUR), vol. 45, no. 3, p. 34, 2013.

[3] T. Mazuryk and M. Gervautz, "Virtual reality-history, applications, technology and future," 1996.

[4] R. Schroeder, "Virtual reality in the real world: history, applications and projections," Futures, vol. 25, no. 9, pp. 963-973, 1993.

[5] C. Cruz-Neira, D. J. Sandin, T. A. DeFanti, R. V. Kenyon, and J. C. Hart, "The CAVE: audio visual experience automatic virtual environment," Communications of the ACM, vol. 35, no. 6, pp. 6473, 1992.

[6] (2019, February 1). university of Minnesota_School of Architecture [Online]. Available: http://arch.design.umn.edu/studentwork/course/3250/virtual-reality.html.

[7] (2019, February 1). University of Michigan_Architecture [Online]. Available: http://taubmancollege.umich.edu/students/course-list/architecture-409-virtual-realitiesrendering-real-time-environments-section-5.

[8] (2019, February 1). Berkeley_ Architecture_Spring 2019 Courses [Online]. Available: https://ced.berkeley.edu/academics/architecture/courses/spring-2019-courses.

[9] (2019, February 1). Cornell university_ Architecture [Online]. Available: http://www.graphics.cornell.edu/academic/cs4654/. 
[10] (2019, February 1). Carnegie Mellon University_ Design [Online]. Available: http://coursecatalog.web.cmu.edu/collegeoffinearts/schoolofdesign/\#coursestext.

[11] (February 1). lowa State University_ Architecture [Online]. Available: http://catalog.iastate.edu/azcourses/arch/arch.pdf.

[12] "Architectural Sciences Program | Western Kentucky University," vol. 2019, 2019.

[13] "FUSE | Western Kentucky University," vol. 2019, 2019.

[14] (2019, February 1). Best VR Headsets of 2019 [Online]. Available: https://www.tomsguide.com/us/best-vr-headsets, review-3550.html.

[15] G. Corke. (2019) Virtual Reality for architecture: a beginner's guide. Available: https://www.aecmag.com/59-features/1166-virtual-reality-for-architecture-a-beginner-s-guide 